\title{
Single particle diversity and mixing state measurements
}

\author{
R. M. Healy ${ }^{1,2}$, N. Riemer ${ }^{3}$, J. C. Wenger ${ }^{2}$, M. Murphy ${ }^{1}$, M. West ${ }^{4}$, L. Poulain ${ }^{5}$, A. Wiedensohler ${ }^{5}$, I. P. O'Connor ${ }^{2}$, \\ E. McGillicuddy ${ }^{2}$, J. R. Sodeau ${ }^{2}$, and G. J. Evans ${ }^{1}$ \\ ${ }^{1}$ Southern Ontario Centre for Atmospheric Aerosol Research, University of Toronto, 200 College Street, Toronto, \\ Ontario, Canada \\ ${ }^{2}$ Department of Chemistry and Environmental Research Institute, University College Cork, Ireland \\ ${ }^{3}$ University of Illinois at Urbana-Champaign, Department of Atmospheric Sciences, Urbana, IL, USA \\ ${ }^{4}$ University of Illinois at Urbana-Champaign, Department of Mechanical Science and Engineering, Urbana, IL, USA \\ ${ }^{5}$ Leibniz Institute for Tropospheric Research, Leipzig, Germany
}

Correspondence to: R. M. Healy (robert.healy@utoronto.ca)

Received: 13 December 2013 - Published in Atmos. Chem. Phys. Discuss.: 14 February 2014

Revised: 23 April 2014 - Accepted: 15 May 2014 - Published: 25 June 2014

\begin{abstract}
A newly developed framework for quantifying aerosol particle diversity and mixing state based on information-theoretic entropy is applied for the first time to single particle mass spectrometry field data. Single particle mass fraction estimates for black carbon, organic aerosol, ammonium, nitrate and sulfate, derived using single particle mass spectrometer, aerosol mass spectrometer and multiangle absorption photometer measurements are used to calculate single particle species diversity $\left(D_{i}\right)$. The average single particle species diversity $\left(D_{\alpha}\right)$ is then related to the species diversity of the bulk population $\left(D_{\gamma}\right)$ to derive a mixing state index value $(\chi)$ at hourly resolution. The mixing state index is a single parameter representation of how internally/externally mixed a particle population is at a given time. The index describes a continuum, with values of 0 and $100 \%$ representing fully external and internal mixing, respectively. This framework was applied to data collected as part of the MEGAPOLI winter campaign in Paris, France, 2010. $D_{i}$ values are low $(\sim 2)$ for fresh traffic and woodburning particles that contain high mass fractions of black carbon and organic aerosol but low mass fractions of inorganic ions. Conversely, $D_{i}$ values are higher $(\sim 4)$ for aged carbonaceous particles containing similar mass fractions of black carbon, organic aerosol, ammonium, nitrate and sulfate. Aerosol in Paris is estimated to be $59 \%$ internally mixed in the size range $150-1067 \mathrm{~nm}$, and mixing state is dependent both upon time of day and air mass origin. Daytime primary emissions associated with vehicular traffic and woodburning result in low $\chi$ values, while enhanced condensation
\end{abstract}

of ammonium nitrate on existing particles at night leads to higher $\chi$ values. Advection of particles from continental Europe containing ammonium, nitrate and sulfate leads to increases in $D_{\alpha}, D_{\gamma}$ and $\chi$. The mixing state index represents a useful metric by which to compare and contrast ambient particle mixing state at other locations globally.

\section{Introduction}

Determination of the chemical composition of ambient aerosol at the single particle level is advantageous for several reasons. Single particle composition information can be used to associate certain single particle types or classes with their respective sources in urban environments (Reinard et al., 2007; Moffet et al., 2008; Snyder et al., 2009; Ault et al., 2010; Dall'Osto et al., 2013). Single particle chemical composition can also be linked directly to climate-relevant aerosol physical properties such as cloud condensation nuclei activity, hygroscopicity, optical absorption and scattering (Furutani et al., 2008; Herich et al., 2009; Moffet and Prather, 2009; Zelenyuk et al., 2010). The composition of single particles can vary significantly across an ambient particle population at a given time, depending upon local and regional sources and the extent of atmospheric processing (Whiteaker et al., 2002; Guazzotti et al., 2003; Ault et al., 2009; Pratt et al., 2011; Cahill et al., 2012; Zauscher et al., 2013). A term that is frequently used in this context is "aerosol mixing state". In this work, we use this term to 
describe how chemical species are distributed amongst the particles present in an aerosol population. In many cases, however, aerosol mixing state is described loosely as "internally mixed" or "externally mixed", even though the reality typically lies somewhere between these two descriptions.

Riemer and West (2013) recently developed a framework for relating single particle chemical composition and bulk aerosol chemical composition in order to derive a quantitative mixing state index $(\chi)$. This approach is based on information-theoretic diversity measures, whereby the Shannon entropy of the chemical species distribution is used to determine both the average single particle species diversity $\left(D_{\alpha}\right)$ and the bulk population species diversity $\left(D_{\gamma}\right)$. The affine ratio of these terms is then used to derive the mixing state index, $\chi$. Such diversity measures have traditionally been applied in the field of ecology to quantify ecosystem biodiversity (Whittaker, 1965), but the approach has also been applied in several other fields to date, including economics and genetics (Attaran, 1986; Rosenberg et al., 2002).

Calculating the species diversity of the bulk population, $D_{\gamma}$, is relatively straightforward, and can be performed by obtaining mass concentrations for the species of interest over a chosen time period using routine aerosol chemical speciation measurements. However, calculating the diversity of a single particle $\left(D_{i}\right.$, a requirement for calculating $\left.D_{\alpha}\right)$ is more challenging, because the relative mass fraction of each chemical species present in that particle must first be determined (Riemer and West, 2013). Thus, measurements of the mass fractions of each chemical species present in each single particle are required in order to determine the mixing state index at a given site.

Single particle mass spectrometers have proven to be suitable for source identification and source apportionment of particulate matter in various environments (Pekney et al., 2006; Eatough et al., 2008; Snyder et al., 2009; Healy et al., 2010). However, attempting quantitative chemical speciation at the single particle level remains problematic due to the high uncertainty associated with the required scaling procedures. Particle counts must be scaled to account for size-dependent detection efficiency, often using estimated effective density values and assuming spherical shape (Qin et al., 2006; Pratt and Prather, 2009). Composition-dependent desorption/ionisation efficiencies and therefore detection efficiencies have also been reported (Kane and Johnston, 2000; Wenzel et al., 2003). At the mass spectral level, compositiondependent matrix effects can lead to differing instrumental sensitivities for the same chemical species depending on the presence or relative abundance of other constituent species within the same particle (Liu et al., 2000). Furthermore, variability in the desorption/ionisation laser power density associated with each pulse can also cause variations in mass spectral ion intensities (Gross et al., 2000; Wenzel and Prather, 2004; Reinard and Johnston, 2008). Despite these significant uncertainties, recent attempts to quantify chemical species based on single particle mass spectral data have proven reasonably successful (Ferge et al., 2006; Pratt et al., 2009; Froyd et al., 2010; Hatch et al., 2011; Jeong et al., 2011; Healy et al., 2013).

The aim of this work was to use a combination of single particle mass spectrometer, aerosol mass spectrometer and multi-angle absorption photometer measurements to estimate the mass fractions of black carbon, organic aerosol, ammonium, nitrate and sulfate present in ambient single particles detected in Paris, France, during the MEGAPOLI winter campaign 2010. These estimates were then used to calculate single particle species diversity $\left(D_{i}\right)$ and hourly average single particle species diversity $\left(D_{\alpha}\right)$ values. Finally, the mixing state index $(\chi)$ was determined for each hour of the measurement period. The methodology described here is expected to be applicable for the determination of aerosol mixing state in other locations globally.

\section{Methods}

\subsection{Instrumentation}

The sampling site and instrumentation used during the MEGAPOLI winter campaign have been described in detail previously (Healy et al., 2012, 2013). Briefly, measurements were performed at the Laboratoire d'Hygiène de la Ville de Paris (LHVP), Paris $\left(48.75^{\circ} \mathrm{N}, 2.36^{\circ} \mathrm{E}\right)$, from 15 January11 February 2010. An aerosol time-of-flight mass spectrometer (ATOFMS, TSI model 3800) (Gard et al., 1997) fitted with an aerodynamic focusing lens (TSI, model AFL100) (Su et al., 2004) was used to collect single particle mass spectra in the size range $150-1067 \mathrm{~nm}$ (aerodynamic diameter, $d_{\mathrm{va}}$ ). Single particles are sampled through a critical orifice and focused in the aerodynamic lens before transmission to the sizing region. Here, $d_{\mathrm{va}}$ for each particle is measured based on its time-of-flight between two sizing lasers (Nd:YAG, $532 \mathrm{~nm}$ ). Particles are subsequently desorbed/ionised using a Q-switched Nd: YAG laser (266 nm, operated at $1.1-1.3 \mathrm{~mJ}$ per pulse), and the resulting positive and negative ions are detected using two time-of-flight mass spectrometers. The instrument was located in an air-conditioned van and sampled aerosol through a stainless steel sampling line at a height of $4 \mathrm{~m}$ above ground level.

Additional instruments were located in an adjacent container. These included a multi-angle absorption photometer (MAAP, Model 5012, Thermo Scientific) (Petzold and Schönlinner, 2004), a high-resolution time-of-flight aerosol mass spectrometer (HR-ToF-AMS, Aerodyne Research Inc.) (DeCarlo et al., 2006), and a twin differential mobility particle sizer (TDMPS) (Birmili et al., 1999). The HRToF-AMS measures mass concentrations of non-refractory aerosol species including ammonium, nitrate, sulfate and organic aerosol. Here the latter refers to the mixture of primary and secondary organic compounds present in the particle phase. A collection efficiency of 0.4 was calculated 
for the HR-ToF-AMS as discussed elsewhere (Crippa et al., 2013). The uncertainty associated with the HR-ToF-AMS and MAAP mass concentration measurements is 30 and $12 \%$, respectively (Bahreini et al., 2009; Crippa et al., 2013; Petzold and Schönlinner, 2004). All instruments located in the container sampled aerosol through a $\mathrm{PM}_{10}$ inlet at $6 \mathrm{~m}$ above ground level. An aerosol diffusion dryer system was used to ensure relative humidity in the sampling line remained below $30 \%$ (Tuch et al., 2009).

\subsection{ATOFMS data analysis}

Approximately 1.75 million single particle mass spectra were collected during the MEGAPOLI winter campaign, and imported into ENCHILADA (Gross et al., 2010) for further analysis. In this work, an adaptation of the quantitative approach described by Healy et al. (2013) has been employed. Healy et al. (2013) previously derived campaignaveraged ATOFMS relative sensitivity factors (RSFs) for organic aerosol, elemental carbon (EC), ammonium, nitrate, sulfate and potassium using a combination of mass spectral marker ion intensities and concurrent bulk aerosol composition measurements. Healy et al. (2013) then applied these RSFs to 10 discrete particle "types" assumed to have static chemical composition.

In this work, RSFs have been calculated at hourly resolution, and applied at the single particle level instead, in an effort to reduce the uncertainty associated with single particle chemical speciation estimates. Hourly average black carbon (BC) mass concentrations were measured using the MAAP and hourly average mass concentrations for ammonium, nitrate, sulfate and organic aerosol (OA) were measured using the HR-ToF-AMS. These data were used to constrain the ATOFMS RSF values as described in the Supplement. The five species chosen represent $>90 \%$ of the composition of $\mathrm{PM}_{2.5}$ measured at the site by mass (Bressi et al., 2013). The average contribution of potassium, sodium and chloride to the measured $\mathrm{PM}_{2.5}$ mass concentration was relatively low $(\sim 3 \%$ ) (Bressi et al., 2013), and therefore these species have not been included in the quantification procedure or in the diversity analysis here. The ATOFMS marker ions used for $\mathrm{OA}, \mathrm{BC}$, ammonium, nitrate and sulfate are the same as those employed previously (Healy et al., 2013). ATOFMS relative peak areas for mass spectral ions were normalised separately for positive and negative ion mass spectra, although combined dual ion mass spectral normalisation produced highly similar results. The RSF values derived for each hour of the campaign were applied to each single particle mass spectrum in that hour to estimate the mass fraction of each chemical species in each single particle. RSF values were found to be reasonably stable across the entire campaign (Fig. S1 in the Supplement). Good agreement was also observed between ATOFMS-derived mass concentration estimates of each chemical species and those measured directly by the HR-ToF-AMS and MAAP instruments, although this is expected because RSF values were calculated at hourly resolution (Figs. S2-S4 in the Supplement).

There are several assumptions involved in the estimation of the mass fraction of each chemical species at the single particle level using this approach that are likely to introduce significant uncertainty in the speciation estimates. First, it is assumed that all particles are composed exclusively of $\mathrm{OA}, \mathrm{BC}$, ammonium, nitrate and sulfate. This is a reasonable simplification in this case, since these species account for $>90 \%$ of the average mass of particulate matter smaller than $2.5 \mu \mathrm{m}$ in diameter $\left(\mathrm{PM}_{2.5}\right)$ in Paris (Bressi et al., 2013). The relative contribution of these five species is expected to be even higher for the size range investigated here $(150-1067 \mathrm{~nm})$, due to a lower contribution from sea salt and crustal material at smaller sizes. Second, it is assumed that the ATOFMS RSF values derived every hour are not significantly dependent upon either particle size or chemical mixing state. While the reasonably low variability of calculated RSF values is encouraging, error is certainly introduced through this assumption (Fig. S1 in the Supplement). Third, when scaling ATOFMS number size distributions, it is assumed that all particles are spherical, with an effective density of $1.5 \mathrm{~g} \mathrm{~cm}^{-3}$ (Healy et al., 2013). A detailed discussion of the hourly RSF values obtained, the marker ions chosen and estimates of uncertainty associated with ATOFMSderived particle speciation are provided in the Supplement. Briefly, the uncertainty associated with hourly mass fraction estimates for $\mathrm{BC}, \mathrm{OA}$, ammonium, sulfate and nitrate are $40,44,76,41$ and $41 \%$, respectively. The highest uncertainty is associated with ammonium, the species for which the ATOFMS also exhibits the poorest sensitivity. It is important to note, however, that uncertainty at the single particle level may be higher, but in the absence of accurate single particle composition measurements for comparison, this cannot be assessed for the ambient data set reported here.

\subsection{Diversity and mixing state index calculations}

The following terminology and formulae relating to information-theoretic entropy, diversity and aerosol mixing state have been described in detail by Riemer and West (2013), but are discussed again here for clarity. For a population of $N$ aerosol particles, each consisting of specific amounts of $A$ distinct aerosol species, the mass of species $a$ in particle $i$ is denoted as $\mu_{i}^{a}$ for $i=1, \ldots, N$ and $a=1, \ldots$, $A$. The total mass of particle $i$, termed $\mu_{i}$, is equal to the sum of the mass of each species present in that particle:

$\mu_{i}=\sum_{a=1}^{A} \mu_{i}^{a}$

and the total mass of species $a$ in the total particle population, termed $\left(\mu^{a}\right)$, is given by 
$\mu^{a}=\sum_{i=1}^{N} \mu_{i}^{a}$

The total mass of the population, $\mu$, is given by

$\mu=\sum_{i=1}^{N} \mu_{i}$

Next, the mass fraction of species $a$ in particle $i$, termed $p_{i}^{a}$ is given by

$p_{i}^{a}=\frac{\mu_{i}^{a}}{\mu_{i}}$

and the mass fraction of particle $i$ in the population, termed $p_{i}$ is

$p_{i}=\frac{\mu_{i}}{\mu}$.

Finally, the mass fraction of species $a$ in the population, termed $p^{a}$, can be expressed as

$p^{a}=\frac{\mu^{a}}{\mu}$.

Calculations of each of these terms are performed by binning the measurement data into hourly periods. The total mass of each particle in the ATOFMS data set, $\mu_{i}$, is calculated based on its diameter, assuming a density of $1.5 \mathrm{~g} \mathrm{~cm}^{-3}$ and spherical shape. Particle counts in each ATOFMS size bin are scaled using concurrent TDMPS data. The mass fraction, $p_{i}^{a}$, of each of the five species of interest (OA, BC, sulfate, nitrate and ammonium) are estimated for each single particle based on its ATOFMS mass spectrum, as discussed in the Supplement, and the sum of these mass fractions is unity.

The chemical composition of the bulk population was monitored directly using the HR-ToF-AMS and MAAP instruments. The total mass of species $a$ in the particle population, $\mu^{a}$, is therefore measured using the AMS/MAAP instruments, and was averaged for each hour of the campaign. There is less uncertainty associated with HR-ToFAMS/MAAP measurements than ATOFMS bulk composition estimates, as discussed in the Supplement, and therefore the former are used to calculate $\mu, \mu^{a}$ and $p^{a}$.

Information-theoretic Shannon entropy is a measure of the uncertainty associated with a random variable and is not to be confused with thermodynamic entropy. The Shannon entropy value associated with each single particle $\left(H_{i}\right)$ can be related to the mass fraction of each species present in that particle as follows:

$H_{i}=\sum_{a=1}^{A}-p_{i}^{a} \ln p_{i}^{a}$.
The average per-particle Shannon entropy $\left(H_{\alpha}\right)$ is given by

$H_{\alpha}=\sum_{i=1}^{N} p_{i} H_{i}$

The Shannon entropy of the entire bulk population $\left(H_{\gamma}\right)$ is given by

$H_{\gamma}=\sum_{a=1}^{A}-p^{a} \ln p^{a}$.

$H_{i}$ and $H_{\alpha}$ are thus calculated using ATOFMS-derived single particle composition estimates, while $H_{\gamma}$ is calculated using the HR-ToF-AMS/MAAP measurements of the bulk population composition. The particle diversity $\left(D_{i}\right)$, or effective number of species in particle $i$, is calculated as follows:

$D_{i}=e^{H_{i}}$

and the average single particle diversity $\left(D_{\alpha}\right)$ is calculated as follows:

$D_{\alpha}=e^{H_{\alpha}}$.

Finally, the bulk population diversity $\left(D_{\gamma}\right)$, or effective number of species in the bulk population, is given by

$D_{\gamma}=e^{H_{\gamma}}$.

These terms can be related to derive the mixing state index $(\chi)$ :

$\chi=\frac{D_{\alpha}-1}{D_{\gamma}-1}$.

Thus, values for single particle diversity are estimated at the single particle level $\left(D_{i}\right)$, averaged across the entire particle population $\left(D_{\alpha}\right)$, and related to the bulk population diversity $\left(D_{\gamma}\right)$ to derive mixing state index values $(\chi)$ at hourly temporal resolution. For a pure external mixture, $D_{i}=D_{\alpha}=1$, so $\chi=0 \%$, while for a pure internal mixture, all particles have the same composition as the bulk aerosol and thus $D_{\alpha}=D_{\gamma}$, so $\chi=100 \%$.

\section{Results and discussion}

\subsection{Relating single particle composition and diversity}

Estimating the mass fractions of $\mathrm{BC}, \mathrm{OA}$, ammonium, nitrate and sulfate present at the single particle level allows for the classification of particles based on their composition and size. The ATOFMS data set was queried based on size and $\mathrm{BC}$ mass fraction for each hour of the campaign and particle counts were scaled using concurrent TDMPS numbersize distribution data. The campaign-average of these hourly 


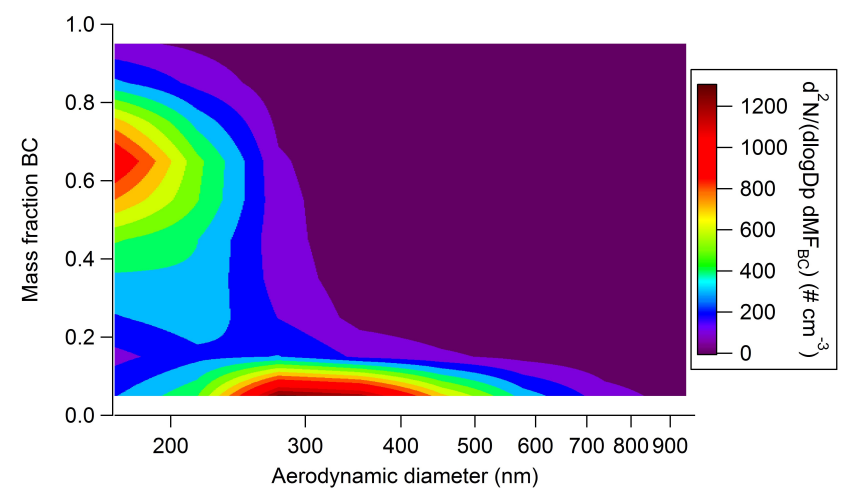

Figure 1. Campaign-averaged dependence of particle number concentration on ATOFMS-derived BC mass fraction and particle diameter.

two-dimensional number distributions is shown in Fig. 1. At the smallest detectable sizes $\left(150-250 \mathrm{~nm}, d_{\mathrm{va}}\right)$, the majority of particles are characterised by $\mathrm{BC}$ mass fractions higher than 0.5 . This is consistent with the fresh, locally emitted combustion particles previously identified and apportioned to vehicular traffic and wood-burning activities in Paris (Healy et al., 2013). At larger sizes (> $250 \mathrm{~nm}$ ), particles are characterised by much lower BC mass fractions $(<0.1)$, and higher inorganic ion content. Condensation of ammonium nitrate on locally emitted combustion particles and transport of ammonium, nitrate, sulfate and secondary organic aerosol from outside Paris have been demonstrated to contribute significantly to the mass concentration of particles $>250 \mathrm{~nm}$ detected at the site (Healy et al., 2013; Crippa et al., 2013).

The particle population can also be classified according to the diversity value $\left(D_{i}\right)$ associated with each single particle as shown in Fig. 2. This value is a representation of the effective number of species present in each single particle (Eq. 10). A particle composed of $100 \%$ BC, for example, will have a $D_{i}$ value of 1 , while a particle consisting of $50 \% \mathrm{OA}$ and $50 \% \mathrm{BC}$ will have a $D_{i}$ value of 2 . A particle consisting of $\mathrm{BC}$ and $\mathrm{OA}$ in unequal proportions will have a diversity value between 1 and 2 . Five species were chosen for this analysis and therefore calculated $D_{i}$ values will lie in the range $1-5$. The majority of particles detected in Paris are characterised by $D_{i}$ values of approximately 2, consistent with combustion particles composed predominantly of BC and OA (Fig. 2). However, as shown in Fig. 3 (top panel), when total particle counts in each size bin are normalised to 1 , an increase in $D_{i}$ with particle diameter is apparent. This is due to the higher inorganic ion content of larger accumulation mode particles (Fig. 3, bottom panel), which results in a more equally weighted contribution from each chemical species at the single particle level, and thus a higher value for $D_{i}$. It follows that single particle diversity is thus expected to increase for carbonaceous particles with time as they accumulate secondary inorganic ions through atmospheric processing (Riemer and West, 2013). Typical

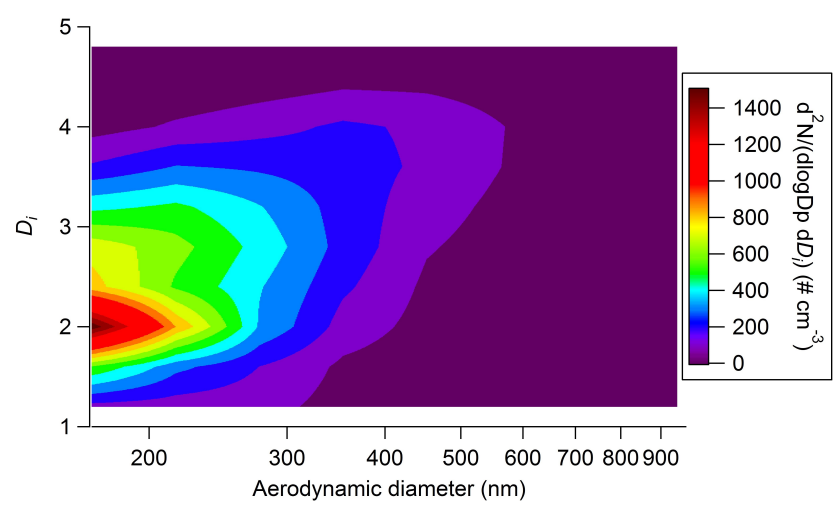

Figure 2. Campaign-averaged dependence of particle number concentration on ATOFMS-derived single particle diversity $\left(D_{i}\right)$ and particle diameter.

single particle mass spectra, associated chemical composition estimates, and calculated $D_{i}$ values for three particles detected during the campaign are given in Fig. 4.

\subsection{Single particle diversity, bulk population diversity and mixing state}

The average single particle diversity, $D_{\alpha}$ (Eq. 11), a representation of the average effective number of species present at the single particle level, was also calculated at hourly resolution using the ATOFMS particle composition estimates. This value can potentially range from 1 (all single particles are pure and contain only 1 species) to 5 (all single particles contain identical mass fractions of all five species). The species diversity of the bulk population, $D_{\gamma}$, was calculated directly from the HR-ToF-AMS and MAAP mass concentration measurements of $\mathrm{BC}, \mathrm{OA}$, ammonium, nitrate and sulfate for each hour of the measurement period (Eq. 12). $D_{\gamma}$ therefore represents the effective number of species present in the bulk population. This value can also range from 1 (only one species is present in the bulk population) to 5 (all five species are present in equal ratios in the bulk population). Thus, $D_{\gamma}$ ignores heterogeneity at the single particle level and describes the diversity of the bulk composition only.

The affine ratio of $D_{\alpha}$ and $D_{\gamma}$ is used to derive the mixing state index $(\chi)$ at hourly resolution (Eq. 13). The mixing state index can potentially range from $0 \%$ when all particles are pure and contain one chemical species (fully externally mixed) to $100 \%$ when all particles have identical mass fractions of each chemical species (fully internally mixed). The relationship between these three terms for the Paris data set is shown in Fig. 5. Mixing state index values range from 37 to $72 \%$, with a mean value of $59 \%$, thus indicating that the particle population measured during the MEGAPOLI winter campaign can never be described as fully internally mixed. It is also apparent that while the bulk population diversity $\left(D_{\gamma}\right)$, at times, approaches the maximum value of 5 , the average single particle diversity $\left(D_{\alpha}\right)$ is rarely greater 


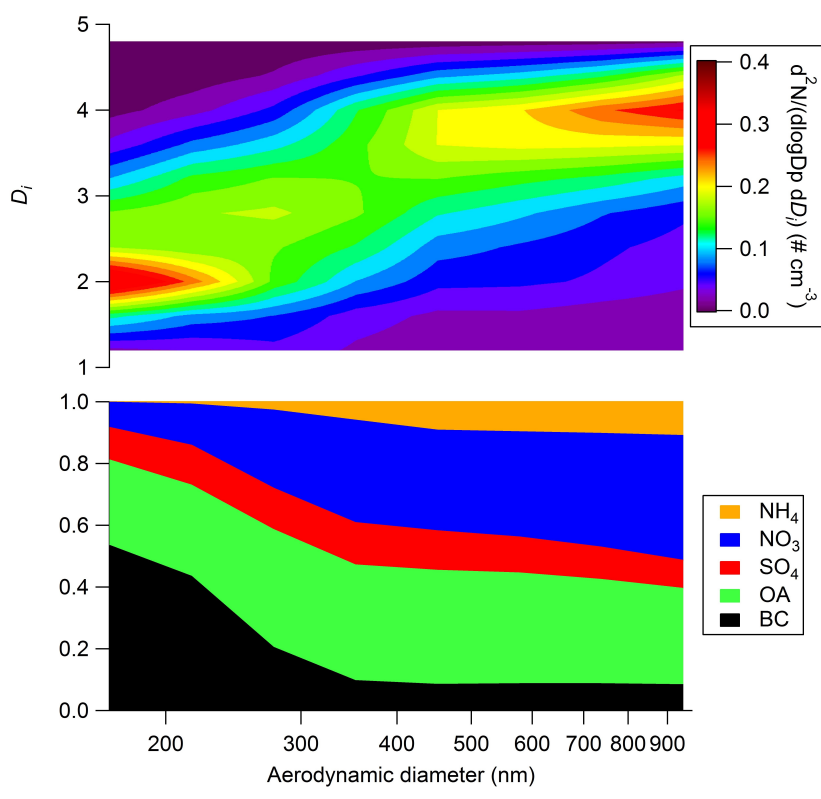

Figure 3. Campaign-averaged dependence of particle number concentration on ATOFMS-derived single particle diversity ( $D_{i}$, counts normalised per size bin) and particle diameter (top panel) and campaign-averaged dependence of ATOFMS-derived estimated single particle composition on particle diameter (bottom panel).

than 3.5. This observation can be explained by heterogeneity in composition between single particles. Smaller particles have higher mass fractions of $\mathrm{BC}$ and $\mathrm{OA}$, while larger particles have higher inorganic mass fractions (Figs. 3 and 4). A variety of different chemical mixing states for particles of the same size has also been previously demonstrated for this data set (Healy et al., 2013). If every single particle had identical chemical composition, $D_{\alpha}$ and $D_{\gamma}$ would be identical, and therefore $\chi$ would equal $100 \%$, representing fully internally mixed aerosol.

\subsection{Dependence of mixing state upon time of day}

$D_{\alpha}, D_{\gamma}$ and the mixing state index $(\chi)$, were observed to be dependent upon time of day, as shown in Fig. 6. Higher values for $D_{\alpha}$ are observed in the early hours of the morning (00:00-04:00 LT). During this period, local emissions associated with vehicular traffic and wood-burning activities are low, and the single particle mass fractions of ammonium and nitrate are increasing through enhanced condensation at lower temperatures (Crippa et al., 2013). The relationship between diurnal ammonium and nitrate mass concentrations and temperature is shown in Fig. S5 in the Supplement. The increase in the mass fractions of ammonium and nitrate present at the single particle level leads to an increase in $D_{\alpha}$. Condensation of ammonium nitrate is also reflected in the simultaneous increase in the bulk population diversity $\left(D_{\gamma}\right)$. Overall, this phenomenon leads to stable, but relatively higher, mixing state index $(\chi)$ values from
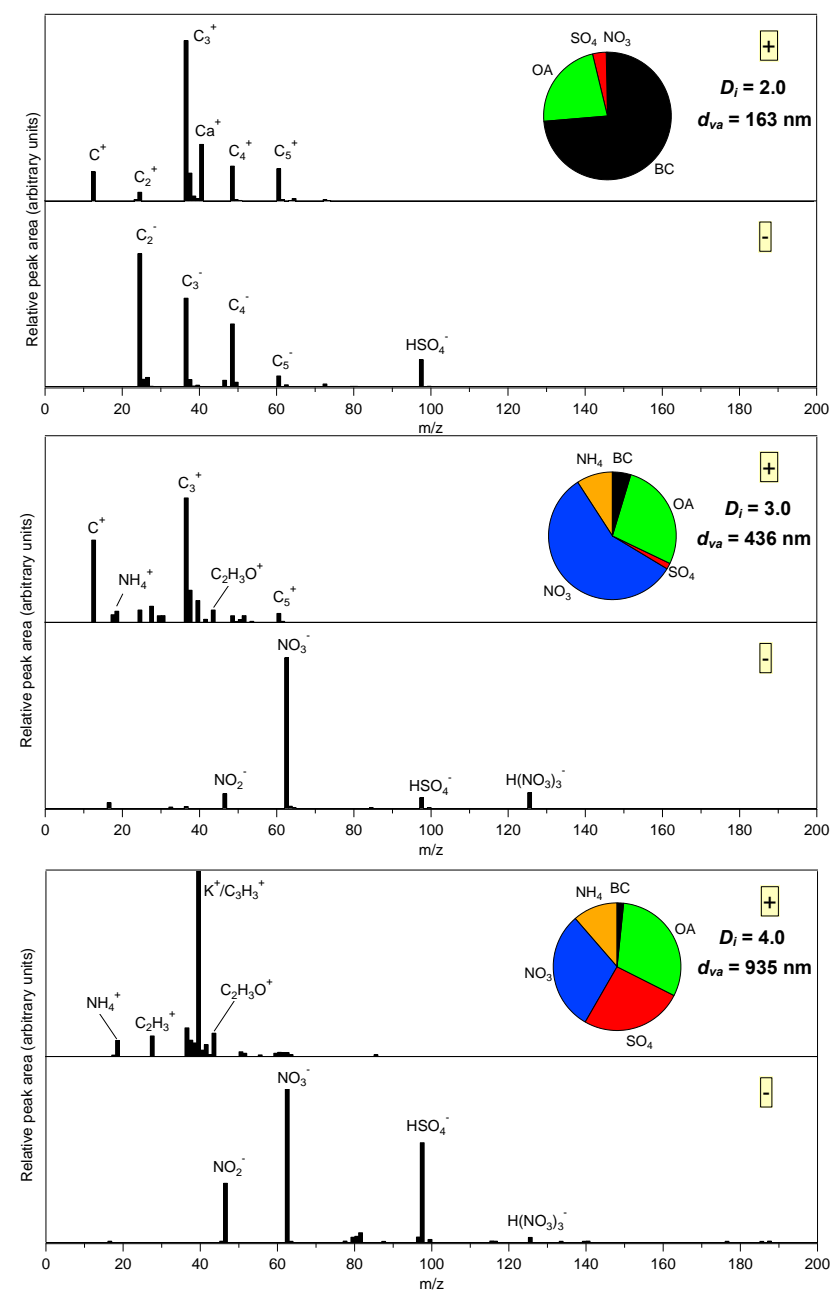

Figure 4. Example single particle mass spectra and chemical composition estimates for particles with calculated $D_{i}$ values of 2.0 (top panel), 3.0 (middle panel) and 4.0 (bottom panel).

00:00-04:00. This behaviour is consistent with that observed for a complex urban plume scenario generated using the particle resolved PartMC-MOSAIC model (Riemer and West, 2013). In that simulation, $D_{\alpha}$ and $D_{\gamma}$ also increased due to condensation of ammonium nitrate on pre-existing carbonaceous particles.

When vehicular traffic emissions increase from 06:00 10:00, $D_{\alpha}$ decreases due to the introduction of high numbers of particles with high $\mathrm{BC}$ and OA mass fractions and low $D_{i}$ values (Fig. 6). Simultaneously, however, $D_{\gamma}$ increases because the increasing mass fraction of $\mathrm{BC}$ present at the bulk population level leads to a more evenly weighted contribution from all five chemical species. Overall, this phenomenon results in a more externally mixed population, and a corresponding decrease in $\chi$ is observed (Fig. 6).

A decrease in $D_{\gamma}$, and to a lesser extent $D_{\alpha}$, is observed at lunchtime (12:00-14:00), when primary cooking organic aerosol contributions are relatively high (Crippa et al., 2013). 


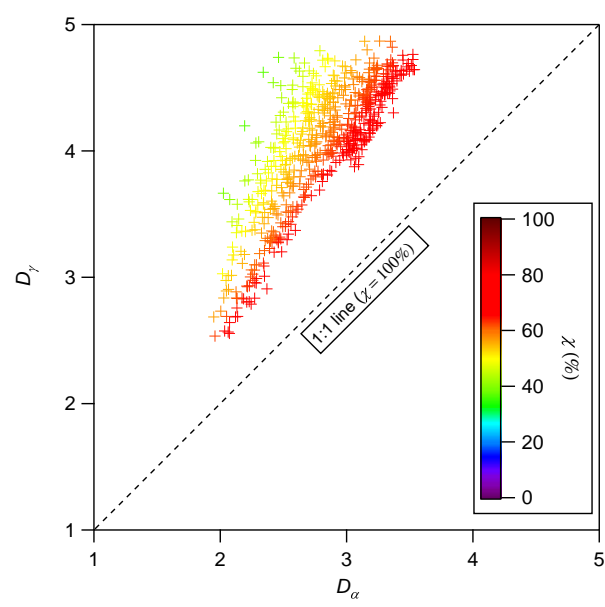

Figure 5. Mixing state diagram demonstrating the relationship between average single particle diversity $\left(D_{\alpha}\right)$, bulk aerosol diversity $\left(D_{\gamma}\right)$ and mixing state $(\chi)$ for each hour of the measurement period.

Cooking-related particles are expected to have low $D_{i}$ values because they are composed predominantly of OA, however the ATOFMS does not detect these particles efficiently (Healy et al., 2013), and therefore their number contribution is expected to be significantly under-represented in the ATOFMS data set. This may be either due to an absence of internally mixed BC or poor absorption efficiency at $266 \mathrm{~nm}$ for cooking-related aliphatic organics (Silva and Prather, 2000). Emissions of pure OA particles are expected to produce a more externally mixed population and therefore result in a decrease in $\chi$. A minor increase in $\chi$ is observed in this case from 12:00-14:00, although it is possible that this may be due to poor ATOFMS desorption/ionisation efficiency for cooking OA particles.

In the evening (16:00-20:00), emissions of fresh primary traffic and wood-burning particles with high BC and OA content and low $D_{i}$ lead to a minor decrease in $D_{\alpha} . D_{\gamma}$ decreases to a greater extent during this period because the high OA mass contribution from wood-burning particles (Crippa et al., 2013; Healy et al., 2013) leads to a less evenly weighted contribution from all five species in the bulk population. From 20:00-23:00, however, primary emissions decrease and condensation of ammonium nitrate leads to an increase in both $D_{\alpha}$ and $D_{\gamma}$. Overall, these phenomena result in an increase in $\chi$ from 16:00-23:00.

The relationship between the average $D_{\gamma}$ and average $D_{\alpha}$ values, sorted by hour of the day ( $N=26$ days), is shown in Fig. 7. At night, condensation of ammonium nitrate and a decrease in primary emissions lead to increases in both $D_{\alpha}$ and $D_{\gamma}$. Early morning vehicular emissions result in a decrease in $D_{\alpha}$ initially, followed by a decrease in both $D_{\alpha}$ and $D_{\gamma}$. Despite this dependence upon time of day, the minimum and maximum hourly average $\chi$ values are 56 and $63 \%$, respectively, indicating that the particle population in Paris remains relatively externally mixed throughout the day.

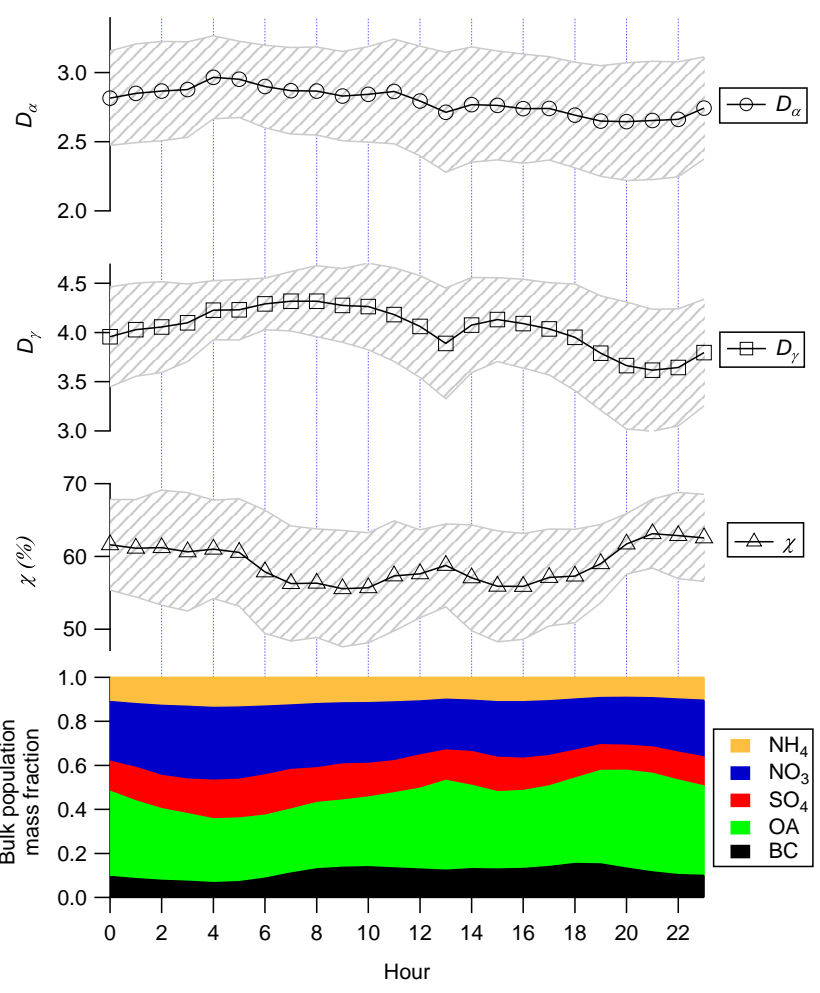

Figure 6. Dependence of average single particle diversity $\left(D_{\alpha}\right)$, average bulk population diversity $\left(D_{\gamma}\right)$, mixing state $(\chi)$ and average bulk population composition upon time of day ( $N=26$ days). The solid lines with the symbols are the campaign-averages for each hour. Shaded areas represent one standard deviation $(1 \sigma)$.

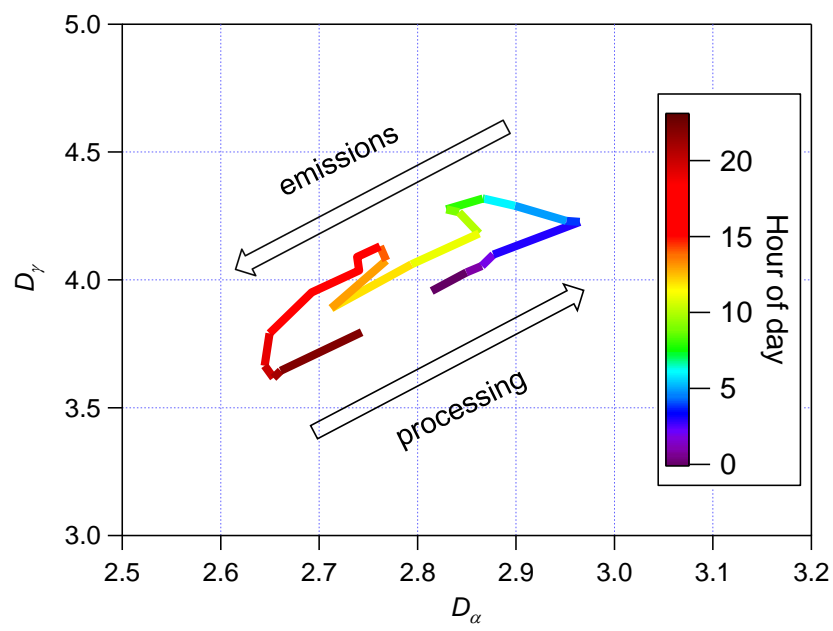

Figure 7. The relationship between average single particle diversity $\left(D_{\alpha}\right)$ and average bulk population diversity $\left(D_{\gamma}\right)$ values sorted by hour of the day $(N=26$ days $)$. 


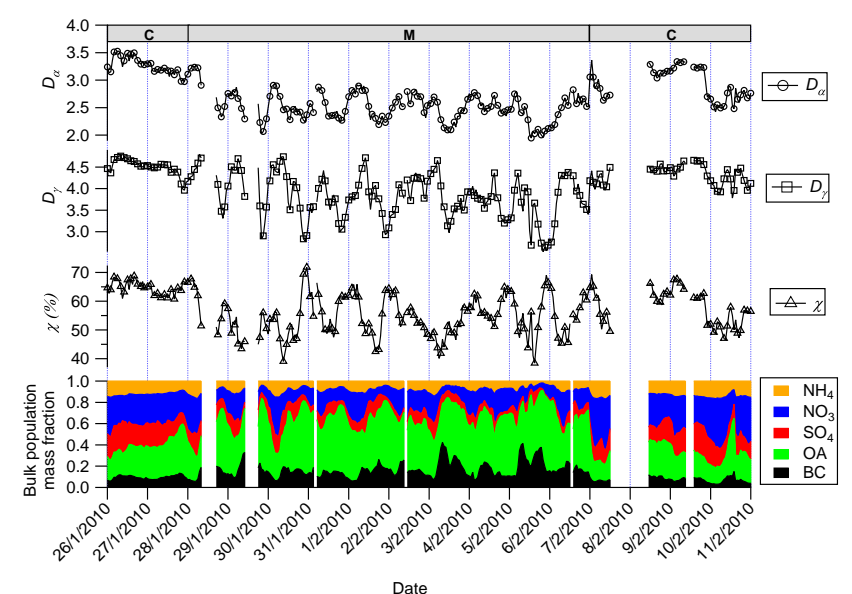

Figure 8. Temporal trends for average single particle diversity $\left(D_{\alpha}\right)$, average bulk population diversity $\left(D_{\gamma}\right)$, mixing state $(\chi)$ and average bulk population composition. "M" and "C" correspond to periods influenced by marine and continental air masses, respectively.

\subsection{Dependence of mixing state upon air mass origin}

The MEGAPOLI winter campaign was also characterised by distinct periods influenced by either marine or continental air masses (Healy et al., 2012; Crippa et al., 2013). Local sources contributed most significantly to aerosol mass concentrations under marine air mass conditions from 28 January 2010-7 February 2010. Advection of significant additional aerosol mass from continental eastern and northwestern Europe was observed from 26-28 January 2010 and from 7-11 February 2010 (Healy et al., 2013). It is clear that air mass origin has a significant impact upon $D_{\alpha}, D_{\gamma}$, and $\chi$, as shown in Fig. 8. When marine air masses prevail, $D_{\alpha}$ is low due to the dominance of local emissions of carbonaceous particles. These particles have low associated $D_{i}$ values due to their low inorganic ion content (Fig. 9). During periods influenced by continental air masses, however, additional contributions of larger, transported particles containing higher ammonium, nitrate and sulfate mass fractions are observed. These particles have much higher $D_{i}$ values (Fig. 9), which in turn leads to higher overall $D_{\alpha}$ values. The larger size and mass of the transported particles also impacts the bulk population composition considerably, leading to higher $D_{\gamma}$ values (Fig. 8). The relationship between $D_{\alpha}, D_{\gamma}$ and air mass origin is shown in Fig. 10. During periods influenced by continental air masses, data points are shifted towards the upperright of the $D_{\alpha}-D_{\gamma}$ space. The average $\chi$ values observed for marine and continental air mass conditions are 55 and $60 \%$, respectively. The latter value remains relatively low, because locally emitted particles with low $D_{i}$ values persist independent of air mass origin (Fig. 9), resulting in a relatively externally mixed particle population at all times. Transported, aged aerosol with high-inorganic ion content is thus expected
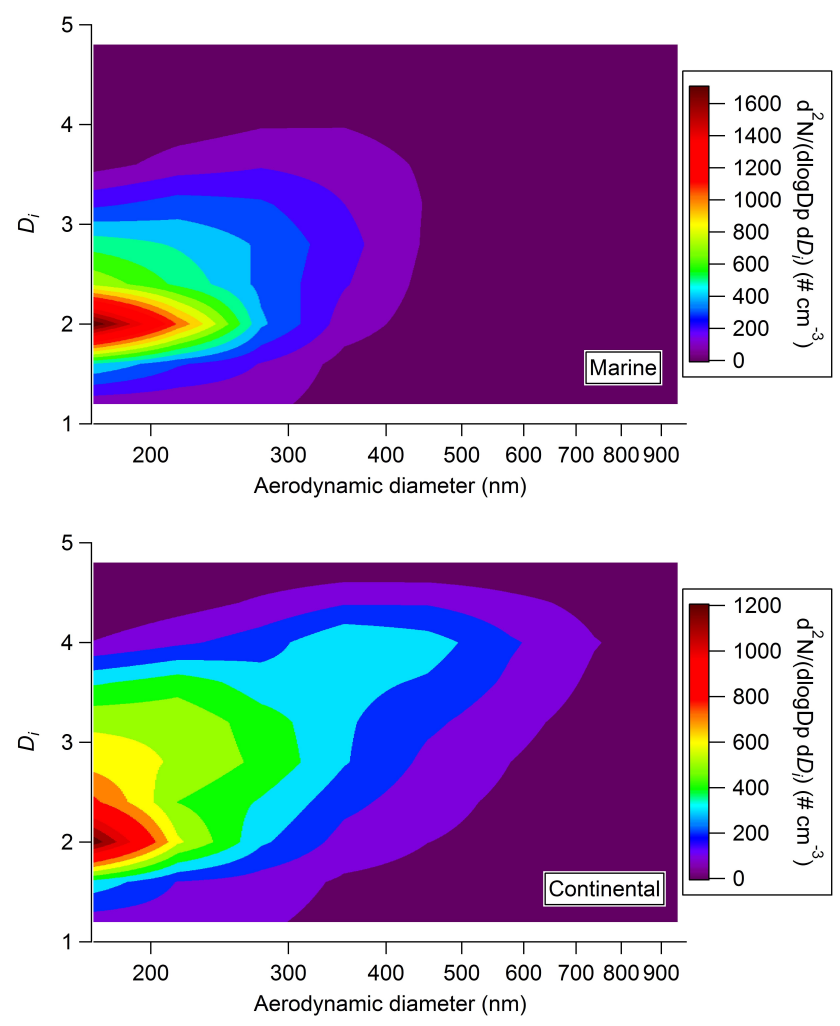

Figure 9. Average dependence of particle number concentration on ATOFMS-derived single particle diversity $\left(D_{i}\right)$ and particle diameter for periods influenced by marine (top) and continental air masses (bottom).

have a higher impact upon the aerosol mixing state index in remote environments, where contributions from local sources are minimal.

\section{Conclusions}

Single particle mass spectrometry, aerosol mass spectrometry and black carbon measurements have been used for the first time to investigate ambient aerosol mixing state using a newly developed framework based on informationtheoretic entropy (Riemer and West, 2013). ATOFMS measurements, constrained using concurrent HR-ToF-AMS and MAAP data, were used to estimate the mass fractions of BC, OA, ammonium, nitrate and sulfate present in single particles detected in Paris, France, during the MEGAPOLI winter campaign. Species mass fractions were then used to calculate single particle species diversity $\left(D_{i}\right)$. Low $D_{i}$ values $(\sim 2)$ were determined for fresh, locally emitted vehicular traffic and wood-burning carbonaceous particles composed predominantly of BC and OA. Higher $D_{i}$ values $(\sim 4)$ were observed for larger, transported particles containing higher mass fractions of inorganic ions. The average diversity of single particles $\left(D_{\alpha}\right)$, and the bulk population diversity $\left(D_{\gamma}\right)$, 


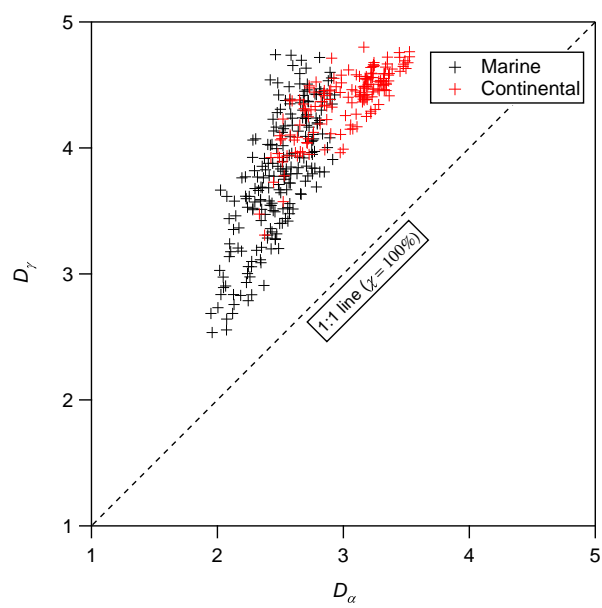

Figure 10. Mixing state diagram demonstrating the relationship between average single particle diversity $\left(D_{\alpha}\right)$ and bulk population diversity $\left(D_{\gamma}\right)$ during periods influenced by marine and continental air masses.

were used to derive the mixing state index $(\chi)$ at hourly resolution. $D_{\alpha}, D_{\gamma}$ and $\chi$ were all found to be dependent upon time of day. $D_{\alpha}$ and $D_{\gamma}$ values were lowest during the daytime and early evening hours when local traffic and woodburning emissions were highest, but increased at night due to a simultaneous decrease in local emissions and enhanced condensation of ammonium nitrate on existing particles. Advection of particles with high ammonium, nitrate and sulfate mass fractions from eastern and northwestern Europe led to significant increases in $D_{\alpha}, D_{\gamma}$ and, to a lesser extent, $\chi$. The average value of $\chi$ determined for aerosol in the size range $150-1067 \mathrm{~nm}$ detected during the MEGAPOLI winter campaign is $59 \%$, and is thus midway between externally and internally mixed.

The approach described here represents a new means by which to compare and contrast aerosol chemical mixing state in various environments globally. Potential applications include investigating changes in the mixing state of aerosol species as a function of plume age. Ambient aerosol diversity measurements are also expected to be useful for constraining or validating regional and global scale models that resolve aerosol chemical mixing state. In particular, this metric will be useful for assessing how differences between models depend on mixing state and how differences between model results and observations depend on mixing state. The description of quantitative diversity and mixing state measures presented here implicitly assumes that "species" should mean "chemical species". Many other possibilities exist, however, including using species subsets, for example particles that do or do not contain BC. Alternative species definitions may be advantageous to relate mixing state to aerosol climate impacts, for example direct radiative forcing. Regarding future measurement efforts, comparisons of $\chi$ values derived using single particle mass spectrometry and off-line single particle analytical techniques will also be valuable.

\section{The Supplement related to this article is available online at doi:10.5194/acp-14-6289-2014-supplement.}

Acknowledgements. This work has been funded by the Higher Education Authority Ireland under PRTLI cycle IV, the Irish Research Council for Engineering and Technology, the EU Seventh Framework Programme FP/2007-2011 (MEGAPOLI) and the Marie Curie Action FP7-PEOPLE-IOF-2011 (Project: CHEMBC, No. 299755). N. Riemer's and M. West's contribution to this work was made possible by US EPA grant 835042 . Its contents are solely the responsibility of the grantee and do not necessarily represent the official views of the US EPA. Further, US EPA does not endorse the purchase of any commercial products or services mentioned in the publication. Meteorological data was provided by Météo-France.

Edited by: M. Beekmann

\section{References}

Attaran, M.: Industrial diversity and economic performance in U.S. areas, Ann. Regional Sci., 20, 44-54, doi:10.1007/bf01287240, 1986.

Ault, A. P., Moore, M. J., Furutani, H., and Prather, K. A.: Impact of Emissions from the Los Angeles Port Region on San Diego Air Quality during Regional Transport Events, Environ. Sci. Technol., 43, 3500-3506, doi:10.1021/es8018918, 2009.

Ault, A. P., Gaston, C. J., Wang, Y., Dominguez, G., Thiemens, M. H., and Prather, K. A.: Characterization of the Single Particle Mixing State of Individual Ship Plume Events Measured at the Port of Los Angeles, Environ. Sci. Technol., 44, 1954-1961, doi:10.1021/es902985h, 2010.

Bahreini, R., Ervens, B., Middlebrook, A. M., Warneke, C., de Gouw, J. A., DeCarlo, P. F., Jimenez, J. L., Brock, C. A., Neuman, J. A., Ryerson, T. B., Stark, H., Atlas, E., Brioude, J., Fried, A., Holloway, J. S., Peischl, J., Richter, D., Walega, J., Weibring, P., Wollny, A. G., and Fehsenfeld, F. C.: Organic aerosol formation in urban and industrial plumes near Houston and Dallas, Texas, J. Geophys. Res.-Atmos., 114, D00F16, doi:10.1029/2008jd011493, 2009.

Birmili, W., Stratmann, F., and Wiedensohler, A.: Design of a DMA-based size spectrometer for a large particle size range and stable operation, J. Aerosol Sci., 30, 549-553, doi:10.1016/s0021-8502(98)00047-0, 1999.

Bressi, M., Sciare, J., Ghersi, V., Bonnaire, N., Nicolas, J. B., Petit, J.-E., Moukhtar, S., Rosso, A., Mihalopoulos, N., and Féron, A.: A one-year comprehensive chemical characterisation of fine aerosol $\left(\mathrm{PM}_{2.5}\right)$ at urban, suburban and rural background sites in the region of Paris (France), Atmos. Chem. Phys., 13, 78257844, doi:10.5194/acp-13-7825-2013, 2013.

Cahill, J. F., Suski, K., Seinfeld, J. H., Zaveri, R. A., and Prather, K. A.: The mixing state of carbonaceous aerosol particles in northern and southern California measured during CARES and CalNex 2010, Atmos. Chem. Phys., 12, 10989-11002, doi:10.5194/acp-12-10989-2012, 2012. 
Crippa, M., DeCarlo, P. F., Slowik, J. G., Mohr, C., Heringa, M. F., Chirico, R., Poulain, L., Freutel, F., Sciare, J., Cozic, J., Di Marco, C. F., Elsasser, M., Nicolas, J. B., Marchand, N., Abidi, E., Wiedensohler, A., Drewnick, F., Schneider, J., Borrmann, S., Nemitz, E., Zimmermann, R., Jaffrezo, J.-L., Prévôt, A. S. H., and Baltensperger, U.: Wintertime aerosol chemical composition and source apportionment of the organic fraction in the metropolitan area of Paris, Atmos. Chem. Phys., 13, 961-981, doi:10.5194/acp-13-961-2013, 2013.

Dall'Osto, M., Ovadnevaite, J., Ceburnis, D., Martin, D., Healy, R. M., O’Connor, I. P., Kourtchev, I., Sodeau, J. R., Wenger, J. C., and O'Dowd, C.: Characterization of urban aerosol in Cork city (Ireland) using aerosol mass spectrometry, Atmos. Chem. Phys., 13, 4997-5015, doi:10.5194/acp-13-4997-2013, 2013.

DeCarlo, P. F., Kimmel, J. R., Trimborn, A., Northway, M. J., Jayne, J. T., Aiken, A. C., Gonin, M., Fuhrer, K., Horvath, T., Docherty, K. S., Worsnop, D. R., and Jimenez, J. L.: Field-Deployable, High-Resolution, Time-of-Flight Aerosol Mass Spectrometer, Anal. Chem., 78, 8281-8289, doi:10.1021/ac061249n, 2006.

Eatough, D. J., Grover, B. D., Woolwine, W. R., Eatough, N. L., Long, R., and Farber, R.: Source apportionment of $1 \mathrm{~h}$ semicontinuous data during the 2005 Study of Organic Aerosols in Riverside (SOAR) using positive matrix factorization, Atmos. Environ., 42, 2706-2719, 2008.

Ferge, T., Karg, E., Schröppel, A., Coffee, K. R., Tobias, H. J., Frank, M., Gard, E. E., and Zimmermann, R.: Fast Determination of the Relative Elemental and Organic Carbon Content of Aerosol Samples by On-Line Single-Particle Aerosol Timeof-Flight Mass Spectrometry, Environ. Sci. Technol., 40, $3327-$ 3335, doi:10.1021/es050799k, 2006.

Froyd, K. D., Murphy, S. M., Murphy, D. M., de Gouw, J. A., Eddingsaas, N. C., and Wennberg, P. O.: Contribution of isoprenederived organosulfates to free tropospheric aerosol mass, P. Natl. Acad. Sci., 107, 21360-21365, doi:10.1073/pnas.1012561107, 2010.

Furutani, H., Dall'osto, M., Roberts, G. C., and Prather, K. A.: Assessment of the relative importance of atmospheric aging on $\mathrm{CCN}$ activity derived from field observations, Atmos. Environ., 42, 3130-3142, 2008.

Gard, E., Mayer, J. E., Morrical, B. D., Dienes, T., Fergenson, D. P., and Prather, K. A.: Real-time analysis of individual atmospheric aerosol particles: Design and performance of a portable ATOFMS, Anal. Chem., 69, 4083-4091, doi:10.1021/ac970540n, 1997.

Gross, D. S., Galli, M. E., Silva, P. J., and Prather, K. A.: Relative Sensitivity Factors for Alkali Metal and Ammonium Cations in Single-Particle Aerosol Time-of-Flight Mass Spectra, Anal. Chem., 72, 416-422, 2000.

Gross, D. S., Atlas, R., Rzeszotarski, J., Turetsky, E., Christensen, J., Benzaid, S., Olsen, J., Smith, T., Steinberg, L., Sulman, J., Ritz, A., Anderson, B., Nelson, C., Musicant, D. R., Chen, L., Snyder, D. C., and Schauer, J. J.: Environmental chemistry through intelligent atmospheric data analysis, Environ. Modell. Softw., 25, 760-769, doi:10.1016/j.envsoft.2009.12.001, 2010.

Guazzotti, S. A., Suess, D. T., Coffee, K. R., Quinn, P. K., Bates, T. S., Wisthaler, A., Hansel, A., Ball, W. P., Dickerson, R. R., Neusüß, C., Crutzen, P. J., and Prather, K. A.: Characterization of carbonaceous aerosols outflow from India and Arabia:
Biomass/biofuel burning and fossil fuel combustion, J. Geophys. Res., 108, 4485, doi:10.1029/2002jd003277, 2003.

Hatch, L. E., Creamean, J. M., Ault, A. P., Surratt, J. D., Chan, M. N., Seinfeld, J. H., Edgerton, E. S., Su, Y., and Prather, K. A.: Measurements of Isoprene-Derived Organosulfates in Ambient Aerosols by Aerosol Time-of-Flight Mass Spectrometry - Part 1: Single Particle Atmospheric Observations in Atlanta, Environ. Sci. Technol., 45, 5105-5111, doi:10.1021/es103944a, 2011.

Healy, R. M., Hellebust, S., Kourtchev, I., Allanic, A., O’Connor, I. P., Bell, J. M., Healy, D. A., Sodeau, J. R., and Wenger, J. C.: Source apportionment of $\mathrm{PM}^{2.5}$ in Cork Harbour, Ireland using a combination of single particle mass spectrometry and quantitative semi-continuous measurements, Atmos. Chem. Phys., 10, 9593-9613, doi:10.5194/acp-10-9593-2010, 2010.

Healy, R. M., Sciare, J., Poulain, L., Kamili, K., Merkel, M., Müller, T., Wiedensohler, A., Eckhardt, S., Stohl, A., Sarda-Estève, R., McGillicuddy, E., O'Connor, I. P., Sodeau, J. R., and Wenger, J. C.: Sources and mixing state of size-resolved elemental carbon particles in a European megacity: Paris, Atmos. Chem. Phys., 12, 1681-1700, doi:10.5194/acp-12-1681-2012, 2012.

Healy, R. M., Sciare, J., Poulain, L., Crippa, M., Wiedensohler, A., Prévôt, A. S. H., Baltensperger, U., Sarda-Estève, R., McGuire, M. L., Jeong, C.-H., McGillicuddy, E., O'Connor, I. P., Sodeau, J. R., Evans, G. J., and Wenger, J. C.: Quantitative determination of carbonaceous particle mixing state in Paris using single-particle mass spectrometer and aerosol mass spectrometer measurements, Atmos. Chem. Phys., 13, 9479-9496, doi:10.5194/acp13-9479-2013, 2013.

Herich, H., Kammermann, L., Friedman, B., Gross, D. S., Weingartner, E., Lohmann, U., Spichtinger, P., Gysel, M., Baltensperger, U., and Cziczo, D. J.: Subarctic atmospheric aerosol composition: 2. Hygroscopic growth properties, J. Geophys. Res., 114, D13204, doi:10.1029/2008jd011574, 2009.

Jeong, C.-H., McGuire, M. L., Godri, K. J., Slowik, J. G., Rehbein, P. J. G., and Evans, G. J.: Quantification of aerosol chemical composition using continuous single particle measurements, Atmos. Chem. Phys., 11, 7027-7044, doi:10.5194/acp-11-70272011, 2011.

Kane, D. B. and Johnston, M. V.: Size and Composition Biases on the Detection of Individual Ultrafine Particles by Aerosol Mass Spectrometry, Environ. Sci. Technol., 34, 4887-4893, doi:10.1021/es001323y, 2000.

Liu, D.-Y., Prather, K. A., and Hering, S. V.: Variations in the Size and Chemical Composition of Nitrate-Containing Particles in Riverside, CA, Aerosol Sci. Technol., 33, 71-86, doi:10.1080/027868200410859, 2000.

Moffet, R. C. and Prather, K. A.: In-situ measurements of the mixing state and optical properties of soot with implications for radiative forcing estimates, P. Natl. Acad. Sci., 106, 11872-11877, doi:10.1073/pnas.0900040106, 2009.

Moffet, R. C., de Foy, B., Molina, L. T., Molina, M. J., and Prather, K. A.: Measurement of ambient aerosols in northern Mexico City by single particle mass spectrometry, Atmos. Chem. Phys., 8, 4499-4516, doi:10.5194/acp-8-4499-2008, 2008.

Pekney, N. J., Davidson, C. I., Bein, K. J., Wexler, A. S., and Johnston, M. V.: Identification of sources of atmospheric PM at the Pittsburgh Supersite, Part I: Single particle analysis and filterbased positive matrix factorization, Atmos. Environ., 40, 411423, 2006. 
Petzold, A. and Schönlinner, M.: Multi-angle absorption photometry-a new method for the measurement of aerosol light absorption and atmospheric black carbon, J. Aerosol Sci., 35, 421-441, doi:10.1016/j.jaerosci.2003.09.005, 2004.

Pratt, K. A. and Prather, K. A.: Real-Time, Single-Particle Volatility, Size, and Chemical Composition Measurements of Aged Urban Aerosols, Environ. Sci. Technol., 43, 8276-8282, doi:10.1021/es902002t, 2009.

Pratt, K. A., Hatch, L. E., and Prather, K. A.: Seasonal Volatility Dependence of Ambient Particle Phase Amines, Environ. Sci. Technol., 43, 5276-5281, doi:10.1021/es803189n, 2009.

Pratt, K. A., Murphy, S. M., Subramanian, R., DeMott, P. J., Kok, G. L., Campos, T., Rogers, D. C., Prenni, A. J., Heymsfield, A. J., Seinfeld, J. H., and Prather, K. A.: Flight-based chemical characterization of biomass burning aerosols within two prescribed burn smoke plumes, Atmos. Chem. Phys., 11, 1254912565, doi:10.5194/acp-11-12549-2011, 2011.

Qin, X., Bhave, P. V., and Prather, K. A.: Comparison of Two Methods for Obtaining Quantitative Mass Concentrations from Aerosol Time-of-Flight Mass Spectrometry Measurements, Anal. Chem., 78, 6169-6178, doi:10.1021/ac060395q, 2006.

Reinard, M. S. and Johnston, M. V.: Ion Formation Mechanism in Laser Desorption Ionization of Individual Nanoparticles, J. Am. Soc. Mass Spectr., 19, 389-399, doi:10.1016/j.jasms.2007.11.017, 2008.

Reinard, M. S., Adou, K., Martini, J. M., and Johnston, M. V.: Source characterization and identification by real-time single particle mass spectrometry, Atmos. Environ., 41, 9397-9409, 2007.

Riemer, N. and West, M.: Quantifying aerosol mixing state with entropy and diversity measures, Atmos. Chem. Phys., 13, 1142311439, doi:10.5194/acp-13-11423-2013, 2013.

Rosenberg, N. A., Pritchard, J. K., Weber, J. L., Cann, H. M., Kidd, K. K., Zhivotovsky, L. A., and Feldman, M. W.: Genetic Structure of Human Populations, Science, 298, 2381-2385, doi:10.1126/science.1078311, 2002.

Silva, P. J. and Prather, K. A.: Interpretation of mass spectra from organic compounds in aerosol time-of-flight mass spectrometry, Anal. Chem., 72, 3553-3562, 2000.

Snyder, D. C., Schauer, J. J., Gross, D. S., and Turner, J. R.: Estimating the contribution of point sources to atmospheric metals using single-particle mass spectrometry, Atmos. Environ., 43, 40334042, 2009.
Su, Y., Sipin, M. F., Furutani, H., and Prather, K. A.: Development and Characterization of an Aerosol Time-of-Flight Mass Spectrometer with Increased Detection Efficiency, Anal. Chem., 76, 712-719, doi:10.1021/ac034797z, 2004.

Tuch, T. M., Haudek, A., Müller, T., Nowak, A., Wex, H., and Wiedensohler, A.: Design and performance of an automatic regenerating adsorption aerosol dryer for continuous operation at monitoring sites, Atmos. Meas. Tech., 2, 417-422, doi:10.5194/amt-2-417-2009, 2009.

Wenzel, R. J. and Prather, K. A.: Improvements in ion signal reproducibility obtained using a homogeneous laser beam for on-line laser desorption/ionization of single particles, Rapid Commun. Mass Sp., 18, 1525-1533, 2004.

Wenzel, R. J., Liu, D.-Y., Edgerton, E. S., and Prather, K. A.: Aerosol time-of-flight mass spectrometry during the Atlanta Supersite Experiment: 2. Scaling procedures, J. Geophys. Res., 108, 8427, doi:10.1029/2001jd001563, 2003.

Whiteaker, J. R., Suess, D. T., and Prather, K. A.: Effects of Meteorological Conditions on Aerosol Composition and Mixing State in Bakersfield, CA, Environ. Sci. Technol., 36, 2345-2353, doi:10.1021/es011381z, 2002.

Whittaker, R. H.: Dominance and Diversity in Land Plant Communities: Numerical relations of species express the importance of competition in community function and evolution, Science, 147, 250-260, doi:10.1126/science.147.3655.250, 1965.

Zauscher, M. D., Wang, Y., Moore, M. J. K., Gaston, C. J., and Prather, K. A.: Air Quality Impact and Physicochemical Aging of Biomass Burning Aerosols during the 2007 San Diego Wildfires, Environ. Sci. Technol., 47, 7633-7643, doi:10.1021/es4004137, 2013.

Zelenyuk, A., Imre, D., Earle, M., Easter, R., Korolev, A., Leaitch, R., Liu, P., Macdonald, A. M., Ovchinnikov, M., and Strapp, W.: In Situ Characterization of Cloud Condensation Nuclei, Interstitial, and Background Particles Using the Single Particle Mass Spectrometer, SPLAT II, Anal. Chem., 82, 7943-7951, doi:10.1021/ac1013892, 2010. 